\title{
Association of transcutaneous $\mathrm{CO}_{2}$ with respiratory support: a prospective double blind observational study in children with bronchiolitis and reactive airway disease
}

\author{
Nadia Shaikh ${ }^{1,2} \cdot$ Sandeep Tripathi ${ }^{1,2} \cdot$ Aviva Whelan $^{1,2} \cdot$ Jessica Ford ${ }^{4} \cdot$ Minchul Kim $^{3} \cdot$ Girish Deshpande $^{1,2}$
}

Received: 6 August 2020 / Accepted: 23 April 2021 / Published online: 29 April 2021

(c) The Author(s), under exclusive licence to Springer Nature B.V. 2021

\begin{abstract}
The use of clinical scoring to assess for severity of respiratory distress and respiratory failure is challenging due to subjectivity and interrater variability. Transcutaneous Capnography $\left(\mathrm{TcpCO}_{2}\right)$ can be used as an objective tool to assess a patient's ventilatory status. This study was designed to assess for any correlation of continuous monitoring of $\mathrm{TcpCO}_{2}$ with the respiratory clinical scores and deterioration in children admitted for acute respiratory distress. A prospective observational study over one year on children aged 2 weeks to 5 years admitted with acute respiratory distress or failure secondary to Bronchiolitis and Reactive airway disease was performed. Continuous $\mathrm{TcpCO}_{2}$ monitoring for upto $48 \mathrm{~h}$ was recorded. Investigators, bedside physicians, respiratory therapists, and nurses were blinded from the transcutaneous trends at the time of data collection. Total of $813 \mathrm{TcpCO}_{2}$ measurements at standard intervals of 30 min were obtained on 38 subjects. Subjects with abnormal $\mathrm{TcpCO}_{2}(>45 \mathrm{mmHg})$ were younger $(6.9 \pm 5.2 \mathrm{vs.} 23.05 \pm 17.7$ months, $)$ and were more likely to be on higher oxygen flow rate $(0.52 \mathrm{~L} / \mathrm{min} / \mathrm{kg}$ vs $0.46 \mathrm{lier} / \mathrm{min} / \mathrm{kg}, \mathrm{p}=0.004)$ and higher $\mathrm{FiO}_{2}(38.4$ vs $33.6, \mathrm{p}<0.001$ using heated high flow nasal cannula. No difference was found in bronchiolitis score or PEW score in subjects with normal and abnormal $\mathrm{TcpCO}_{2}$. A small but statistically significant increase in $\mathrm{TcpCO}_{2}$ was observed at the escalation of care. Even though odds of escalation of care are higher with abnormal $\mathrm{TcpCO}_{2}(\mathrm{OR} 1.92)$, this difference did not reach statistical significance. $\mathrm{pCO}_{2}$ can provide additive information for non-invasive clinical monitoring of children requiring varying respiratory support; however, it does not provide predictive value for escalation or de-escalation of care.
\end{abstract}

Keywords Transcutaneous capnometry $\cdot$ Blood gas monitoring $\cdot$ Pediatric unit $\cdot$ Patient safety $\cdot$ Pediatric early warning scores $\cdot$ Respiratory failure

\section{Introduction}

Nadia Shaikh

nshaikh@uic.edu

1 Department of Pediatrics, University of Illinois College of Medicine at Peoria, 530 NE Glen Oak Ave., Peoria, IL 61637, USA

2 Department of Pediatrics, OSF St. Francis Medical Center, Peoria, IL, USA

3 Division of Internal Medicine, University of Illinois College of Medicine at Peoria, Peoria, IL, USA

4 Department of Pediatrics, Marshall University, Huntington, WV, USA
Acute respiratory decompensation is often challenging to identify in children hospitalized with respiratory distress of varying severity [1]. Many children's hospitals, including ours, practice clinical scoring tools assessed by bedside nurses [bronchiolitis score, asthma scores, pediatric early warning score (PEW), etc.] for early recognition of deterioration. In conjunction with the physician judgment, these scores guide the clinical decision to escalate or deescalate care. Most of these scores are based on assessing the rapidity of breathing, signs of exhaustion, use of accessory muscles and vital signs, which in children may not be reliable, and have shown interrater variability and observer bias in previous studies [2]. While oxygenation can be measured by pulse oximetry, these clinical scores have no tool to assess ventilatory effort in children. Thus, there is a need for an 
objective tool for monitoring children who may be at risk of rapid deterioration.

Measurement of the partial pressure of carbon dioxide in arterial blood $\left(\mathrm{PaCO}_{2}\right)$ is the gold standard for the assessment of gas exchange in critically sick children. For patients without arterial access, end-tidal $\mathrm{CO}_{2}$, and Transcutaneous $\mathrm{CO}_{2}\left(\mathrm{TcpCO}_{2}\right)$ monitoring devices are commonly used to assess the ventilatory status. End-tidal $\mathrm{CO}_{2}$ is used during surgery and in intensive care units where endotracheal tube is placed and is helpful in monitoring ventilation, apnea or obstruction and dislocation of endotracheal tube [3]. It is also used in conjunction with standard nasal cannula oxygen during procedural sedation to monitor ventilation, apnea as well as airway obstruction. However, it has limited application inpatient on non-invasive modes of ventilation such as Heated High Flow Nasal Cannula (HHFNC) or Nasal Intermittent Ventilation (NIV) or mask ventilation as they are amenable for air leaks and have an element of $\mathrm{CO}_{2}$ washout, thus making $\mathrm{CO}_{2}$ measurements unreliable [4]. $\mathrm{TcpCO}_{2}$ is often used as an alternate noninvasive measure of ventilation for patients on mechanical ventilation in pediatric and neonatal ICUs as $\mathrm{TcpCO}_{2}$ correlates well with arterial blood gases [3, 5-10].

There is, however, a paucity of knowledge on the use of $\mathrm{TcpCO}_{2}$ in patients hospitalized on non-invasive respiratory support like standard flow or heated high flow nasal cannula. Since $\mathrm{TcpCO}_{2}$ results are shown to be comparable to arterial blood gases, we wanted to study its use as a surrogate marker in predicting clinical respiratory decompensation. We hypothesized that $\mathrm{TcpCO}_{2}$ would be elevated $(>45 \mathrm{mmHg}$ ) in patients who require escalation of care and lower values can help guide de-escalation of care. The objectives of our study were, 1.To assess the utility of $\mathrm{TcpCO}_{2}$ monitoring in children with acute respiratory distress and; 2 . To study the correlation of $\mathrm{TcpCO}_{2}$ with the clinical scores to guide escalation and de-escalation of care.

\section{Methods}

This prospective double-blind observational study was performed at a 136-bed tertiary academic children's hospital in the Midwest region of the United States. We included 53 children aged between 2 weeks to 5 years admitted to the pediatric floor, intermediate unit, and intensive care unit with a primary diagnosis of acute respiratory distress or respiratory failure secondary to bronchiolitis and reactive airway disease who were not intubated on arrival, utilizing a convenient random sampling. Patients admitted with acute respiratory illness with no co-morbidities affecting the respiratory system were included in the study. We excluded children with pre-existing chronic lung or heart disease, neuromuscular abnormalities, and prematurity $<36$ weeks.
These conditions are prone to having hypercapnia at baseline impacting the study results thus, were excluded [11, 12]. No laboratory testing was performed at the beginning of the study. Children on mechanical ventilation were also not included as they were considered to be on maximal support. The study was conducted for a period of 12 months from January 2019 to December 2019 after approval from the Institutional Review Board. Every patient was assessed on admission by the investigator for inclusion in the study and was enrolled after obtaining informed consent from the parents. Most subjects admitted with acute bronchiolitis and reactive airway disease exhibit disease progression over the first few days of hospitalization and thus the investigators decided to monitor all patients for at least $48 \mathrm{~h}$. Before the study, education was provided to define the roles of the respiratory therapists (RT) and nurses on study participants.

The $\mathrm{TcpCO}_{2}$ probe (SDMS, SenTec AG, Switzerland) was placed by the RTs. To minimize errors with placement and calibration, only RTs were assigned to monitor, recalibrate, and replace the transcutaneous sensors at the specific sites approved by the manufacturer. The sensor was allowed to calibrate and equilibrate before the continuous monitoring was initiated. The first $30 \mathrm{~min}$ of data were not included in the analysis to allow for an equilibration time.

Patient's initial level of care unit (general floor, intermediate, or critical care unit) on admission were recorded with vitals and $\mathrm{TcpCO}_{2}$ by the RT. Following this, bedside physicians and nurses, as well as study investigators, were blinded from the $\mathrm{TcpCO}_{2}$ trends by turning off the monitor screens and alarms. The $\mathrm{TcpCO}_{2}$ monitors continued to record the trends internally. During the study period, $\mathrm{TcpCO}_{2}$ data was not available to the clinical team on the study participants and routine vitals were taken per unit protocols.

Any management decision including escalation or deescalation of respiratory support was made by the clinical team on clinical judgment. Escalation of clinical care was defined as an increased requirement of $\mathrm{FiO}_{2}$ or flow rate or increased respiratory support to require non-invasive or invasive ventilation. Since the escalation to intermediate or intensive care units depends on institutional guidelines, this parameter was not considered as an "escalation of care" in our study. At our institution, escalation is marked by one of the three timestamps documented in the electronic medical records which include, a. Increase in the PEW score, b. Notification to pediatric emergency response team and c. Orders placed for the need of higher oxygen support. The time points at which any escalation in respiratory support occurred were recorded with the vitals and $\mathrm{TcpCO}_{2}$ by the $\mathrm{RT}$ or bedside nurses. On completion of the monitoring of each patient, the $\mathrm{TcpCO}_{2}$ report was reviewed for trends.

For patients on high flow nasal cannula, the "set" $\mathrm{FiO}_{2}$ was considered as the delivered $\mathrm{FiO}_{2}$. It is, however, not possible to accurately predict the delivered $\mathrm{FiO}_{2}$ on a patient on 
a regular nasal cannula and "off the wall" oxygen. To minimize the wide variability in $\mathrm{FiO}_{2}$ delivery by standard flow nasal cannula, we assigned $\mathrm{FiO}_{2}$ of $0.21,0.24,0.30,0.35$, $0.40,0.45$ and 0.48 to flow rates of $<1-6 \mathrm{~L} / \mathrm{min}$ respectively, based on prior published calculated values [13]. Since the effective ventilator support by flow is dependent on the size of the patient, the flow rate was divided by patients' recorded weight for comparative analysis.

For analysis, the sample was split into two groups: normal ( $\mathrm{TcpCO}_{2}<=45 \mathrm{mmHg}$ ) and abnormal $\left(\mathrm{TcpCO}_{2}>45 \mathrm{mmHg}\right)$. Standard descriptive statistics included mean with standard deviation and median with Inter Quartile Ranges (IQR) for continuous variables, and percentage for categorical variables. T-test was conducted for continuous variables and chi-square test was conducted for categorical variables. The statistical analysis was conducted for outcome variables using regression analysis with random effect for continuous outcomes and logistic regression for binary outcomes. Since there are multiple time point observations among the same patients, regression analysis for panel data was employed for whole analyses. Outcome variables included $\mathrm{FiO}_{2}$ level, $\mathrm{PEW}$, bronchiolitis Score, Flow, and escalation/de-escalation of care. Univariate and multivariable statistical analyses were conducted on the above outcome variables. A key covariate was a dichotomous variable on whether $\mathrm{TcpCO}_{2}$ is normal or abnormal. Other covariates included age, sex, weight, and flow. Statistical analysis was conducted using STATA 12 version (StataCorp. College Station, TX) and JMP V 14.2.0 (SAS, Carry, NC) A p-value of less than 0.05 was considered statistically significant.

\section{Results}

A total of 82 subjects were assessed for eligibility. After informed consent, 53 subjects were enrolled in the study. Eight subjects were withdrawn per parental requests (three provided no specific reason, two parents did not want extra cords, two were not comfortable with the sensor while one subject complained of a skin rash). However, due to missing $\mathrm{TcpCO}_{2}$ waveforms ( $>30 \mathrm{~min}$ at a stretch), data from 7 subjects were excluded. Thirty-eight subjects (38) were included in the final analysis (Fig. 1).

A total of $813 \mathrm{TcpCO}_{2}$ measurements were obtained on the study subjects, with a median of 13 per patient (range 10-75). and each $\mathrm{TcpCO}_{2}$ reading was taken at a $30 \mathrm{~min}$ interval. The distribution of $\mathrm{TcpCO}_{2}$ values is provided in Fig. 2. The median age of the patient was 14.5 months (IQR 5, 30.2, range 1.5-62 months). Of the 38 subjects, 22 were male $(57.8 \%)$, and the median weight of the patient was $9.75 \mathrm{~kg}$ (IQR 7.2, 12.2, range 4.47-23 kg). Of the 38 patients, 10 were admitted in the PICU, 19 in the general

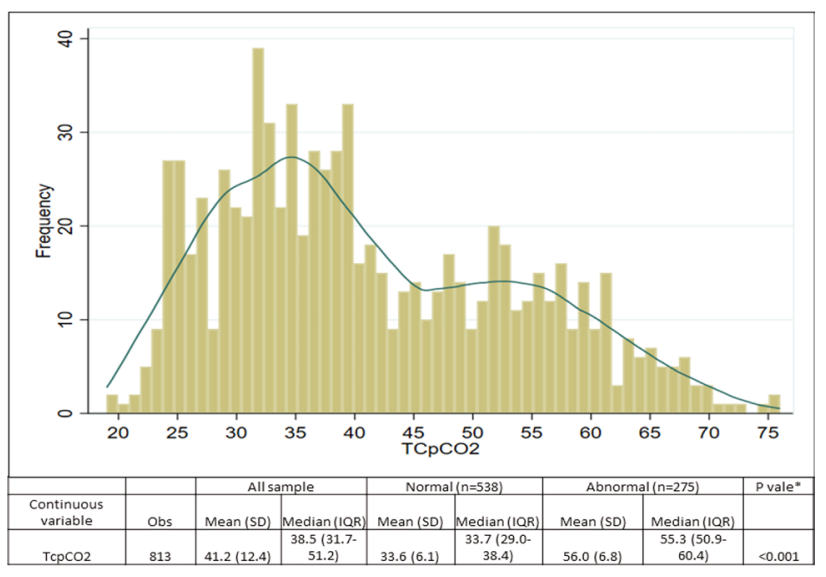

Fig. 1 Distribution of $\mathrm{TcpCO}_{2}$ values in patients with normal and abnormal values. *t test for continuous variables and chi-square test for categorical variable

pediatric unit while 9 were on the intermediate floor. There were 20 instances where either the flow or the $\mathrm{FiO}_{2}$ was escalated, while 60 occurrences of de-escalation were observed. Among these 20 escalation events, 5 subjects required a Pediatric emergency response team (PERT) to be assisted eventually were transferred to a higher level of care for monitoring. Of all the patients, one patient was escalated to NIMV and one required mechanical ventilation. (Table 1).

A total of 275 (33.8\%) $\mathrm{TcpCO}_{2}$ values were abnormal (>45), while $538(66.1 \%)$ were normal (Table 2). Overall mean $\mathrm{FiO}_{2}$ was $34.8 \pm 14.2$ while the flow rate adjusted for weight was $0.47 \pm 0.35 \mathrm{~L} / \mathrm{min} / \mathrm{kg}$. The mean bronchiolitis score and PEW score were $2.67 \pm 1.82$ and $4.14 \pm 2.17$, respectively. Subjects with abnormal $\mathrm{TcpCO}_{2}$ were significantly younger compared to subjects with normal $\mathrm{TcpCO}_{2}$ (mean age of $6.9 \pm 5.2$ vs. $23.05 \pm 17.7$ ) months, $\mathrm{p}<0.001$ and as expected had lower mean weight. There was a significant gender difference in the two groups with a proportionally larger number of males in the normal transcutaneous group (58.9\% vs $45.8 \%, p=0.004)$. There was no significant difference in the mean $\mathrm{FiO}_{2}$, bronchiolitis score, or PEW score between the two groups by univariate comparison; however, the patients with abnormal $\mathrm{TcpCO}_{2}$ had been on a much higher mean flow rate $(0.69 \pm 0.32 \mathrm{~L} / \mathrm{min} / \mathrm{kg}$ vs. $0.35 \pm 0.31 \mathrm{~L} / \mathrm{min} / \mathrm{kg}, \mathrm{p}<0.001$ ) (Table 2).

On multivariable analysis after adjusting for age, weight, sex, and flow rate, subjects with abnormal $\mathrm{TcpCO}_{2}$ had significantly higher predicted $\mathrm{FiO}_{2}$ than subjects with normal $\mathrm{TcpCO}_{2}$ (38.4 vs $33.6, \mathrm{P}<0.001$, coefficient $4.78,95 \%$ confidence interval 2.87-6.68). This difference was observed in all age groups, although the difference was highest for children more than one year of age. Similarly, subjects with abnormal $\mathrm{TcpCO}_{2}$ had a higher predicted flow rate compared to subjects with normal $\mathrm{TcpCO}_{2}(0.52 \mathrm{~L} / \mathrm{min} / \mathrm{kg}$ vs. $0.46 \mathrm{~L} /$ $\mathrm{min} / \mathrm{kg}, \mathrm{p}=0.004$, coefficient $0.06,95 \%$ confidence interval 
Fig. 2 Flowchart of patients included in the study

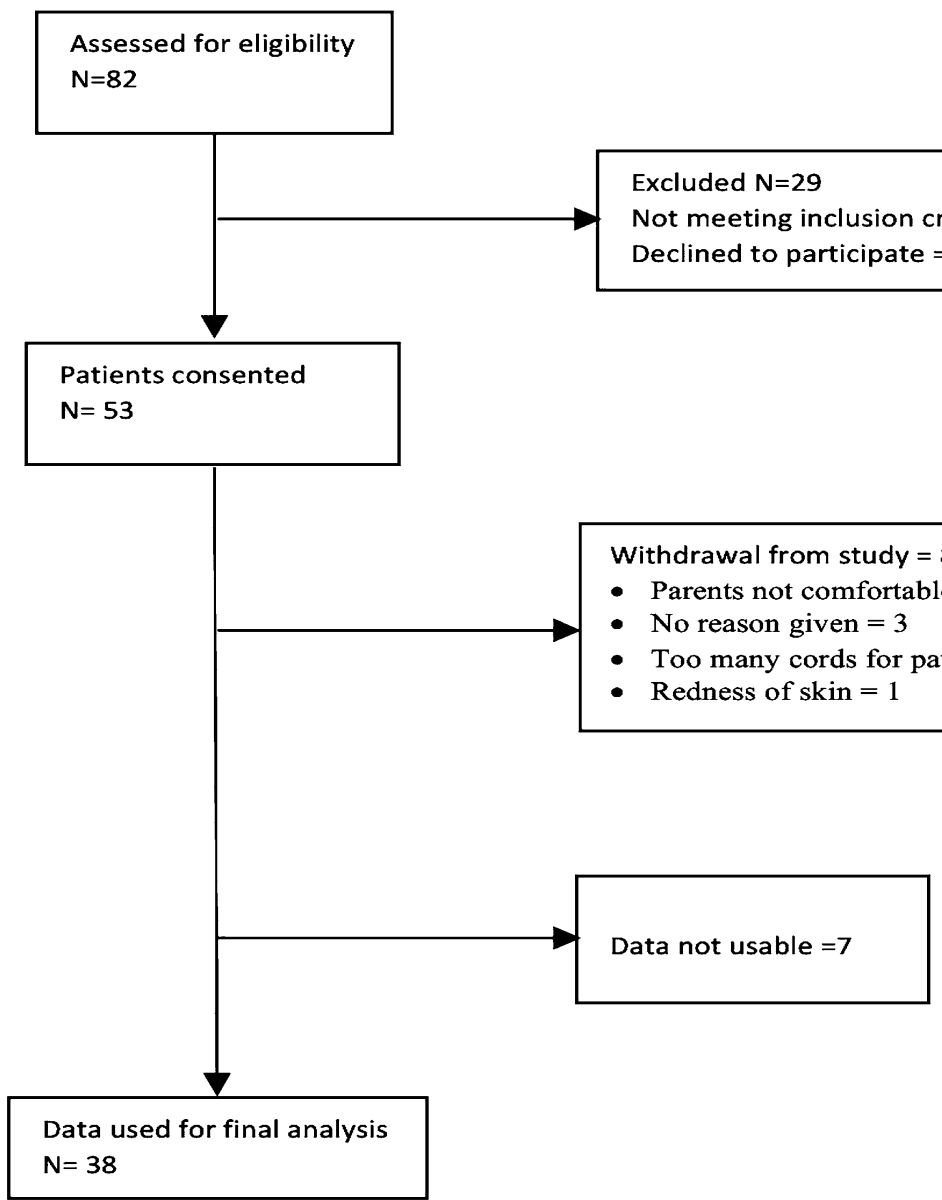

Table 1 Descriptive statistics of population with escalation to higher oxygen support or transfer to higher level of care

\begin{tabular}{ll}
\hline Initial Admitting Unit (N) & $\mathrm{N}=38$ \\
General Pediatrics (GP) & 19 \\
Pediatric Intermediate (PIC) & 9 \\
Pediatric Intensive Care Unit (PICU) & 10 \\
Total number of escalation (N) & 20 \\
Transfers to higher level of care (N) & 6 \\
GP to PIC & 2 \\
GP to PICU & 3 \\
PIC to PICU & \\
Escalation in PICU & 1 \\
Escalation to Non Invasive Intermittent Mandatory Ventila- & 1 \\
$\quad$ tion (NIMV) & 1 \\
Escalation to mechanical ventilation & \\
No transfers & 7 \\
FiO2 or flow escalation (N) & 5 \\
Pediatric emergency response (N) & \\
\hline
\end{tabular}

0.02-0.11) after adjusting for weight, age, and sex. Although the predicted flow rate was higher in subjects with abnormal $\mathrm{TcpCO}_{2}$ for all age groups, it did not reach statistical significance for children $<1$-year age. After adjusting for age, weight, sex, and flow rate, no significant difference was observed between abnormal and normal $\mathrm{TcpCO}_{2}$ for bronchiolitis score and PEW score for total population or in different age brackets (Table 3).

Other factors significantly associated with higher $\mathrm{FiO}_{2}$ requirements were age (coefficient 0.35 , 95\% C.I 0.03-0.68) and flow/weight (coefficient 21.5, 95\% C.I 18.6-24.4). The flow/weight was the only covariate with a significant association with bronchiolitis score and PEW score (Table 4).

Age, weight, sex, and flow/weight-adjusted predicted $\mathrm{TcpCO}_{2}$ was significantly higher during instances of escalation of care [43.2 vs $40.3 \Delta 2.8$ (95\% C.I 0.2-5.4)]. There was, however, no difference in predicted $\mathrm{TcpCO}_{2}$ during the de-escalation of care. After doing subgroup analysis by age (less than one year and more than one year), the difference did not reach statistical significance for either age bracket (Table 5).

For subjects with abnormal $\mathrm{TcpCO}_{2}$, the odds of escalation of care were 1.92 for all age groups, 3.41 for $<12$ months, and 1.03 for $>12$ months. While the odds of de-escalation were 1.14 for all age groups and 0.82 and 1.48 for 12 months, respectively. The odds ratio, however, 
Table 2 Descriptive statistics of the sample population and observations with normal and abnormal transcutaneous $\mathrm{CO} 2$
Table 3 Predicted means for normal and abnormal transcutaneous $\mathrm{CO} 2$ by multi variable regression analysis

\begin{tabular}{llllc}
\hline & $\begin{array}{l}\text { All } \\
(\mathrm{N}=813)\end{array}$ & $\begin{array}{l}\text { Normal } \\
(\mathrm{N}=538)\end{array}$ & $\begin{array}{l}\text { Abnormal } \\
(\mathrm{N}=275)\end{array}$ & P value \\
\hline Age (months) & $17.6 \pm 16.6$ & $23.05 \pm 17.7$ & $6.98 \pm 5.22$ & $<0.0001$ \\
Weight (kilograms) & $10.07 \pm 4.2$ & $11.27 \pm 4.49$ & $7.74 \pm 2.16$ & $<0.001$ \\
Males & $443(54.4 \%)$ & $317 / 538(58.9 \%)$ & $126 / 275(45.8 \%)$ & 0.0004 \\
FiO2 & $34.8 \pm 14.2$ & $35.45 \pm 15.6$ & $33.77 \pm 11.17$ & 0.07 \\
Flow/weight & $0.47 \pm 0.35$ & $0.35 \pm 0.31$ & $0.69 \pm 0.32$ & $<0.001$ \\
Bronchiolitis score & $2.67 \pm 1.82$ & $2.71 \pm 1.96$ & $2.61 \pm 1.59$ & 0.74 \\
& $(\mathrm{~N}=127)$ & $(\mathrm{N}=78)$ & $(\mathrm{N}=49)$ & 0.52 \\
PEW score & $4.14 \pm 2.17$ & $4.21 \pm 2.34$ & $4.0 \pm 1.77$ & $(\mathrm{~N}=50)$ \\
& $(\mathrm{N}=158)$ & $(\mathrm{N}=108)$ & & \\
\hline
\end{tabular}

\begin{tabular}{|c|c|c|c|c|c|c|c|}
\hline & & Normal & Abnormal & Difference & $\mathrm{P}$ value & $95 \%$ C.I & \\
\hline \multirow[t]{3}{*}{$\mathrm{FiO} 2$} & $\begin{array}{l}\text { All } \\
(\mathrm{N}=813)\end{array}$ & 33.65 & 38.43 & 4.78 & $<0.001$ & 2.87 & 6.68 \\
\hline & $\begin{array}{l}<12 \text { months } \\
(\mathrm{N}=415)\end{array}$ & 26.80 & 29.51 & 2.72 & $<0.001$ & 1.36 & 4.07 \\
\hline & $\begin{array}{l}>12 \text { months } \\
(\mathrm{N}=398)\end{array}$ & 41.60 & 50.70 & 9.09 & $<0.001$ & 5.03 & 13.15 \\
\hline \multirow[t]{3}{*}{ Flow/weight } & $\begin{array}{l}\text { All } \\
(\mathrm{N}=813)\end{array}$ & 0.46 & 0.52 & 0.06 & 0.004 & 0.02 & 0.11 \\
\hline & $\begin{array}{l}<12 \text { months } \\
(\mathrm{N}=415)\end{array}$ & 0.46 & 0.51 & 0.05 & 0.107 & -0.01 & 0.11 \\
\hline & $\begin{array}{l}>12 \text { months } \\
(\mathrm{N}=398)\end{array}$ & 0.47 & 0.55 & 0.09 & 0.005 & 0.03 & 0.15 \\
\hline \multirow[t]{3}{*}{ Bronchiolitis score } & $\begin{array}{l}\text { All } \\
(\mathrm{N}=127)\end{array}$ & 2.83 & 3.04 & 0.21 & 0.421 & -0.30 & 0.72 \\
\hline & $\begin{array}{l}<12 \text { months } \\
(\mathrm{N}=70)\end{array}$ & 2.13 & 2.56 & 0.43 & 0.252 & -0.31 & 1.18 \\
\hline & $\begin{array}{l}>12 \text { months } \\
(\mathrm{N}=57)\end{array}$ & 3.55 & 3.47 & -0.08 & 0.805 & -0.74 & 0.57 \\
\hline \multirow[t]{3}{*}{ PEW score } & $\begin{array}{l}\text { All } \\
(N=158)\end{array}$ & 4.13 & 4.23 & 0.10 & 0.765 & -0.54 & 0.74 \\
\hline & $\begin{array}{l}<12 \text { months } \\
(\mathrm{N}=74)\end{array}$ & 2.86 & 3.11 & 0.25 & 0.564 & -0.59 & 1.09 \\
\hline & $\begin{array}{l}>12 \text { months } \\
(\mathrm{N}=84)\end{array}$ & 5.11 & 5.17 & 0.07 & 0.895 & -0.90 & 1.03 \\
\hline
\end{tabular}

did not reach statistical significance after adjusting for age, weight, sex, and flow rate (Table 6).

\section{Discussion}

In this prospective observational study on 38 subjects, we have shown that patients with abnormal $\mathrm{TcpCO}_{2}$ are more likely to be on higher oxygen flow rate and higher $\mathrm{FiO}_{2}$. $\mathrm{TcpCO}_{2}$ does not correlate with bronchiolitis score or PEW score. There is a small but statistically significant increase in $\mathrm{TcpCO}_{2}$ at the time of the escalation of care. Even though odds of escalation of care are higher with abnormal $\mathrm{TcpCO}_{2}$, this difference does not reach statistical significance. To the best of our knowledge, this is the only prospective, blinded study comparing children's continuous $\mathrm{TcpCO}_{2}$ with respiratory support and progression.

To date, $\mathrm{TcpCO}_{2}$ has been studied extensively in patients on mechanical ventilation but there are very few studies that have investigated its utilization outside of the critical care areas. Gal et al. studied the utilization of $\mathrm{TcpCO}_{2}$ in children with bronchiolitis in emergency and pediatric units. They estimated the correlation of $\mathrm{TcpCO}_{2}$ with $\mathrm{pCO}_{2}$ and compared it with the clinical parameters and children's ventilation ability. Similar to our results, Gal et al. reported a negative correlation of $\mathrm{TcpCO}_{2}$ with weight and age [14].

With the current management of acute respiratory failure, flow rates, and $\mathrm{FiO}_{2}$ are titrated to the evolving respiratory 
Table 4 Parameter estimates (coefficients) by multi variable regression analysis
Table 5 Comparison of predicted $\mathrm{tCO} 2$ values during escalation/de-escalation and no action by multi variate logistic regression

\begin{tabular}{|c|c|c|c|c|c|c|}
\hline Outcome & $\mathrm{N}$ & Covariates & Coefficient & $P$ value & $95 \%$ C.I & \\
\hline \multirow[t]{6}{*}{$\mathrm{FiO} 2$} & \multirow[t]{6}{*}{813} & Abnormal TCO2 & 4.78 & 0.00 & 2.87 & 6.68 \\
\hline & & Age & 0.35 & 0.03 & 0.03 & 0.68 \\
\hline & & Male & -2.34 & 0.36 & -7.44 & 2.76 \\
\hline & & Weight & 1.08 & 0.11 & -0.26 & 2.42 \\
\hline & & Flow/weight & 21.5 & 0.00 & 18.63 & 24.43 \\
\hline & & Constant & 7.68 & 0.07 & -0.63 & 16.0 \\
\hline \multirow[t]{5}{*}{ Flow/weight } & \multirow[t]{5}{*}{813} & Abnormal TCO2 & 0.06 & 0.004 & 0.02 & 0.11 \\
\hline & & Age & 0.00 & 0.64 & -0.02 & 0.01 \\
\hline & & Male sex & -0.02 & 0.83 & -0.22 & 0.18 \\
\hline & & Weight & 0.02 & 0.43 & -0.03 & 0.07 \\
\hline & & Constant & 0.31 & 0.05 & -0.01 & 0.63 \\
\hline \multirow[t]{6}{*}{ Bronchiolitis score } & \multirow[t]{6}{*}{127} & Abnormal TCO2 & 0.21 & 0.42 & -0.30 & 0.72 \\
\hline & & Age & 0.04 & 0.40 & -0.05 & 0.13 \\
\hline & & Male sex & 0.27 & 0.58 & -0.71 & 1.25 \\
\hline & & Weight & 0.07 & 0.67 & -0.24 & 0.37 \\
\hline & & Flow/weight & 2.51 & 0.00 & 1.68 & 3.33 \\
\hline & & Constant & 0.35 & 0.69 & -1.41 & 2.11 \\
\hline \multirow[t]{6}{*}{ PEW Score } & \multirow[t]{6}{*}{158} & Abnormal TCO2 & 0.10 & 0.76 & -0.54 & 0.74 \\
\hline & & Age & -0.01 & 0.78 & -0.08 & 0.06 \\
\hline & & Male sex & 0.17 & 0.74 & -0.88 & 1.22 \\
\hline & & Weight & 0.25 & 0.07 & -0.03 & 0.52 \\
\hline & & Flow/weight & 3.13 & 0.00 & 2.20 & 4.07 \\
\hline & & Constant & 0.28 & 7.53 & -1.44 & 1.99 \\
\hline
\end{tabular}

\begin{tabular}{lllcrrr}
\hline & & Predicted TCO2 & Difference & P value & \multicolumn{2}{c}{ 95\% C.I } \\
\hline All ages & No action (reference) & 40.3 & & & & \\
$(\mathrm{~N}=813)$ & Escalation & 43.2 & 2.8 & 0.032 & 0.2 & 5.4 \\
& De-escalation & 40.3 & -0.1 & 0.945 & -1.6 & 1.5 \\
$<12$ months & No action (reference) & 47.3 & & & & \\
$(\mathrm{~N}=415)$ & Escalation & 50.0 & 2.7 & 0.077 & -0.3 & 5.8 \\
& De-escalation & 44.8 & -2.5 & 0.072 & -5.2 & 0.2 \\
$>12$ months & No action (reference) & 33.6 & & & & \\
$(\mathrm{~N}=398)$ & Escalation & 36.6 & 3.1 & 0.197 & -1.6 & 7.8 \\
& De-escalation & 34.0 & 0.5 & 0.613 & -1.4 & 2.3 \\
\hline
\end{tabular}

Table 6 Odds of escalation/ de-escalation VS no action based on transcutaneous $\mathrm{CO} 2$ more than 45 (multivariable analysis adjusted for age, weight, flow and sex by panel data logit model)

\begin{tabular}{llllllr}
\hline & & $\mathrm{N}$ & Odds ratio & P value & 95\% CI & \\
\hline All age & Escalation & 753 & 1.92 & 0.319 & 0.53 & 6.87 \\
& De-escalation & 793 & 1.14 & 0.748 & 0.52 & 2.50 \\
$<12$ months & Escalation & 397 & 3.41 & 0.133 & 0.69 & 16.85 \\
& De-escalation & 401 & 0.82 & 0.745 & 0.25 & 2.69 \\
& Escalation & 356 & 1.03 & 0.977 & 0.12 & 8.75 \\
& De-escalation & 392 & 1.48 & 0.490 & 0.49 & 4.46 \\
\hline
\end{tabular}

status to achieve effective oxygen delivery at the alveolar level. Oxygen saturation, however, has been found to have a lower impact on the respiratory drive than $\mathrm{CO}_{2}$ concentrations in the blood and overall $\mathrm{SaO}_{2}$ is a poor predictor of respiratory distress $[15,16]$. With the increased oxygen support, ventilation status can be masked by higher 
oxygen saturation and may delay the identification of treatment failure. In our study, both the flow rates and $\mathrm{FiO}_{2}$ were titrated by the bedside RN or RT or physician based on maintaining normal oxygen saturations and breathing support.

Even though we did not record $\mathrm{SaO}_{2}$, it is conceivable that transcutaneous levels were abnormal in children even as oxygen saturations were normal, particularly in children on higher $\mathrm{FiO}_{2}$ and flow rates which represents an indirect measure of severity and progression of the disease.

No prior study has previously correlated PEW and bronchiolitis scores to $\mathrm{TcpCO}_{2}$, although other scores have been studied. In a study on children with severe croup, reduction in the $\mathrm{TcpCO}_{2}$ values and clinical scores (Croup scores) was noted following the administration of inhaled epinephrine [17]. Our results did not show any association of $\mathrm{TcpCO}_{2}$ with PEW and Bronchiolitis scores. A possible explanation for this difference could be the lack of stridor and cyanosis in children with bronchiolitis, which as compared to heart rate, respiratory rate, and work of breaking are more obvious signs of severity. Gal et al. reported an increase in $\mathrm{TcpCO}_{2}$ levels with the disease severity scores but in contrast to our study, they assessed the clinical scores only at the initiation of the study while our data has been longitudinal, spanning over different provider shifts bringing in the variation in clinical experience and possible interobserver discordance.

PEW score has been recognized as a comprehensive system that supports multidisciplinary communication amongst clinical teams and increases the sense of awareness for risk of deterioration, however, there is a lack of data to prove the benefits of patient outcomes [18, 19]. Our findings suggest that the inclusion of $\mathrm{TcpCO}_{2}$ as an auxiliary tool to these clinical models can assist in trending hypoventilation and may augment accuracy and clinical decisions.

One of the objectives of our study was to determine if $\mathrm{TcpCO}_{2}$ can be used to assess clinical deterioration and assist with escalation and de-escalation of respiratory support. The data showed a small but statistically significant increase in $\mathrm{TcpCO}_{2}$ at the time of the escalation of care. Even though odds of escalation of care are higher with abnormal $\mathrm{TcpCO}_{2}$, this difference does not reach statistical significance and may require future studies to establish any relationship.

Previously the use of $\mathrm{TcpCO}_{2}$ has been found cumbersome if performed intermittently, due to frequent need of recalibration. We noted that continuous $\mathrm{TcpCO}_{2}$ monitoring was more convenient as that prevented frequent recalibration. Also, while we did not include patients with sensitive skin or eczema, no burn or skin injury was reported.

Our study has several limitations in addition to being a single-center study. Our institution's protocol for the initiation and adjustment of any respiratory support is dependent on physician's or bedside RN's clinical discretion and flow was not titrated based on a standard protocol. Second, in contrast to HHFNC where $\mathrm{FiO}_{2}$ and flow rate can be specified, the $\mathrm{FiO}_{2}$ delivered through a standard nasal cannula at variable flow rates cannot be specifically quantified. Delivered $\mathrm{FiO}_{2}$ by $\mathrm{NC}$ in our study was estimated based on literature and not directly measured. Third, even though we did not include the first 30-min $\mathrm{TcpCO}_{2}$ value in our data to take into account for equilibration time of $\mathrm{CO}_{2}$ between capillary blood and transcutaneous monitor probe, we could not omit the values for other times as they were not time-stamped at point when the probes were changed; and it is possible that we could have recorded few inaccurate values while the equilibration was still taking place. Similarly, our spot measurements of $\mathrm{TcpCO}_{2}$ at the time of escalation may have had a lag of 60-90 s due to the diffusion of $\mathrm{CO}_{2}$ through the skin. This was not taken into account to avoid errors of time-lapse between vitals and $\mathrm{TcpCO}_{2}$.

\section{Conclusion}

$\mathrm{TcpCO}_{2}$ can provide additive information for non-invasive clinical monitoring of children requiring varying respiratory support that require closer monitoring due to their age or ventilatory status. However, it does not provide predictive value for escalation nor de-escalation of care. Future wellcontrolled studies with associative predictors of respiratory support failure and comorbidities are needed to investigate the actual clinical application on a larger scale.

Acknowledgements The authors thank SenTec AG for equipment and technical support, and the nursing and the Respiratory staff of the children's hospital for their collaboration in the performance of the study.

Author contributions GD conceptualized and designed the study, carried out the initial analysis, reviewed and revised the manuscript, and approved the final manuscript as submitted. NS drafted the initial manuscript, conducted the literature search, reviewed and revised the manuscript, and approved the final manuscript as submitted. ST conducted the final analyses, conceptualized portions of the study, reviewed and revised the manuscript, critically reviewed the manuscript for important intellectual content, and approved the final manuscript as submitted. AW and JF reviewed and revised the manuscript, critically reviewed the manuscript for important intellectual content, and approved the final manuscript as submitted. MK developed the statistical framework for the study and conducted the statistical analysis and approved the final manuscript as submitted.

Funding The authors have no financial relationships relevant to this article to disclose. SenTec, AG (Switzerland) supported this research with monitors, disposables, and technical support with no monetary compensation. SenTec was not involved in study design, data interpretation, or manuscript preparation.

Data availability All data will be provided if requested to review.

Code availability VSTATs. 


\section{Declarations}

Conflict of interest The authors have no conflicts of interest to disclose.

Compliance with ethical standards This retrospective chart review study involving human participants was in accordance with the ethical standards of the institutional and national research committee and with the 1964 Helsinki Declaration and its later amendments or comparable ethical standards. The Human Investigation Committee (IRB) of University approved this study.

\section{References}

1. Kohei H, Pate BM, Mansbach JM, Macias CG, Fisher ES, Piedra PA, Camargo CA. Risk factors for requiring intensive care among children admitted to ward with bronchiolitis. Acad Pediatr. 2015;15(1):77-81. https://doi.org/10.1016/j.acap.2014.06.008.

2. Rubin S, Ghuman A, Deakers T, Khemani R, Ross P, Newth CJ. Effort of breathing in children receiving high-flow nasal cannula. Pediatr Crit Care Med. 2014;15(1):1-6. https://doi.org/10.1097/ PCC.0000000000000011.

3. TOBIAS JD. Transcutaneous carbon dioxide monitoring in infants and children. Pediatr Anesth. 2009;19(5):434-44. https://doi.org/ 10.1111/j.1460-9592.2009.02930.x.

4. Cuvelier A, Grigoriu B, Molano LC, Muir J. Limitations of transcutaneous carbon dioxide measurements for assessing long-term mechanical ventilation. Chest. 2005;127(5):1744-8. https://doi. org/10.1378/chest.127.5.1744.

5. Tobias JD. Non-invasive carbon dioxide monitoring in infants and children with congenital heart disease: end-tidal versus transcutaneous techniques: 18. Pediatr Crit Care Med. 2005;6(1):107. https://doi.org/10.1097/00130478-200501000-00070.

6. Mukhopadhyay S, Maurer R, Puopolo KM. Neonatal transcutaneous carbon dioxide monitoring-effect on clinical management and outcomes. Respir Care. 2016;61(1):90-7. https://doi.org/10.4187/ respcare.04212.

7. Hazenberg A, Zijlstra JG, Kerstjens HAM, Wijkstra PJ. Validation of a transcutaneous $\mathrm{CO}(2)$ monitor in adult patients with chronic respiratory failure. Respir Int Rev Thorac Dis. 2011;81(3):242.

8. Lagerkvist A, Sten G, Redfors S, Holmgren D, et al. Repeated blood gas monitoring in healthy children and adolescents by the transcutaneous route. Pediatr Pulmonol. 2003;35(4):274-9. https://doi.org/10.1002/ppul.10263.
9. Ruiz Y, Farrero E, Córdoba A, González N, Dorca J, Prats E. Transcutaneous carbon dioxide monitoring in subjects with acute respiratory failure and severe hypercapnia. Respir Care. 2016;61(4):428-33. https://doi.org/10.4187/respcare.04283.

10. Yıldızdaş D, Yapıcıoğlu H, Yılmaz HL, Sertdemir Y. Correlation of simultaneously obtained capillary, venous, and arterial blood gases of patients in a paediatric intensive care unit. Arch Dis Child. 2004;89(2):176-80.

11. Travers CP, Abman SH, Carlo WA. Control of breathing in preterm infants neonatal ICU and beyond. Am J Respir Crit Care Med. 2018;197(12):1518-20.

12. Nitu M, Montgomery G, Eigen H. Acid-base disorders. Pediatr Rev. 2011;32(6):240-51.

13. Wettstein RB, Shelledy DC, Peters JI. Delivered oxygen concentrations using low-flow and high-flow nasal cannulas. Respir Care. 2005;50(5):604.

14. Gal S, Riskin A, Chistyakov I, Shifman N, Srugo I, Kugelman A, et al. Transcutaneous PCOsub2 monitoring in infants hospitalized with viral bronchiolitis. Eur J Pediatr. 2015;174(3):319-20.

15. Ross PA, Newth CJL, Khemani RG. Accuracy of pulse oximetry in children. Pediatrics. 2014;133(1):22-9. https://doi.org/10.1542/ peds.2013-1760.

16. Ralston SL, Lieberthal AS, Meissner HC, American Academy of Pediatrics, et al. Clinical practice guideline: the diagnosis, management, and prevention of bronchiolitis. Pediatrics. 2014;134(5):e1474-502.

17. Tschupp A, Fanconi S. A combined ear sensor for pulse oximetry and carbon dioxide tension monitoring: accuracy in critically ill children. Anesth Analg. 2003;96(1):82-4. https://doi.org/10.1097/ 00000539-200301000-00017.

18. Chapman SM, Maconochie IK. Early warning scores in paediatrics: an overview. Arch Dis Child. 2019;104(4):395-9. https://doi. org/10.1136/archdischild-2018-314807.

19. Lambert V, Matthews A, MacDonell R, Fitzsimons J. Paediatric early warning systems for detecting and responding to clinical deterioration in children: a systematic review. BMJ Open. 2017;7(3):e014497. https://doi.org/10.1136/bmjop en-2016-014497.

Publisher's Note Springer Nature remains neutral with regard to jurisdictional claims in published maps and institutional affiliations. 